\title{
Model predictive control for buildings with active one-pipe hydronic heating
}

\author{
Jiri Dostal ${ }^{1,2, *}$ and Tomas Baumelt ${ }^{1}$ \\ ${ }^{1}$ University Centre for Energy Efficient Buildings of Technical University in Prague, 27343 Bustehrad, Czech Republic \\ ${ }^{2}$ Department of Control Engineering, Czech Technical University in Prague, 12000 Prague, Czech Republic
}

\begin{abstract}
One-pipe hydronic heating systems in their active (decentralized pumping) form promise great benefits over traditional two-pipe variable volume systems, and even more so over variable air volume systems. The heat exchanger units are connected in series, which presents its challenges and opportunities. This paper presents a model predictive controller capable of harnessing as many benefits as there is in the system when used in a building. A case study on a small office building illustrates the capabilities and validates the concept.
\end{abstract}

\section{Introduction}

Energy consumption in buildings and households in the European Union as well as in the developed countries in general amounts up to $40 \%$ of the total energy usage [ 1 , 2]; from which as much as $75 \%$ is reported not to be used up efficiently [14].

In May 2018, an EU directive on building energy performance and energy efficiency [3] was published. The directive recalls the EU commitment to developing a sustainable, competitive, secure and decarbonized energy system by 2050 . To meet the goal, the EU aims to decarbonize the building stock responsible for $36 \%$ of all $\mathrm{CO}_{2}$ emissions in the Union. The principle 'energy efficiency first' therein projects into the rise of near-zero energy buildings (NZEB) in the future. The envelope improvements, however, should be accompanied by an appropriate technical system development.

Newly, for example, buildings should include control systems capable of regulating temperature in every room or designated heated zone. Further, by 2025, all nonresidential dwellings with installed HVAC power over $290 \mathrm{~kW}$ will be mandatorily equipped with a building automation and control system (BACS) capable of continuous monitoring, analysis and providing suggestions for energy efficiency improvements. Residential sector will be driven to use effective control ensuring optimal generation, distribution, storage and use of energy. Heat generators are to be designed for typical or average conditions, instead of extreme conditions, to ensure maximum energy efficiency year-long; heat generation shall be adjustable without a loss of efficiency [3].

Model predictive control of HVAC systems can decrease energy consumption by $17-24 \%[7,16]$ and is being applied to nowadays buildings as a mean to improve energy efficiency.
The purpose of this paper is to show the capabilities of such advanced control of a building with an active onepipe hydronic network.

The paper is organized as follows: a full description of the one-pipe hydronic network is given, followed by a mathematical model of the heating system and building envelope. Model predictive controller with its application to an EnergyPlus model of a real office building is presented by the end of the paper. This work extends the thesis [41].

\subsection{Hydronic network topologies}

A hydronic distribution network is an assembly of pipes, pumps, fittings, valves, heat exchangers and heat sources arranged to distribute heat from a heat source to thermal zones using a heat transfer liquid.

Regarding regulation, we can divide hydronic systems into passive and active. Passive systems usually contain one pressure source (pump), and throttling valves control the flow through terminals. Active systems incorporate a circulator assigned to every heat exchanger. Flow through the heat exchanger is there controlled by pump operation. In a two-pipe hydronic heating system (also called parallel), there is common piping routed from a heat supply to all heat exchangers. When neglecting the temperature decrease in the piping, all the heat exchangers are supposed to have the same inlet temperature. A common return piping is then collecting all the heat exchanger returns. For further description of the various topologies, see [24, 26].

\subsection{Active one-pipe hydronic system}

A one-pipe hydronic heating system consists of one primary circuit in which multiple secondary circuits (circuit with a heat exchanger) are connected in series, see Fig. 1. Input and output pipes of the secondary circuit connect to the primary pump in close succession;

\footnotetext{
* Corresponding author: jiri.dostal@cvut.cz
} 


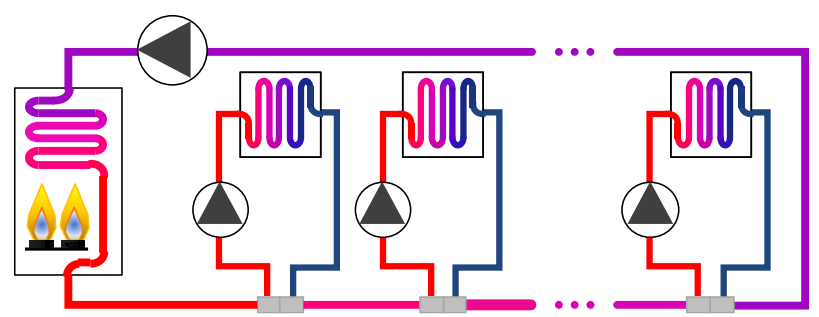

Fig. 1. Active one-pipe hydronic heating network. Secondary circuits are connected in the primary circuit in series; secondary flow is controlled by a secondary pump.

generally realized by a twin-tee fitting. Returning liquid from the secondary circuit is mixed therein with the primary liquid consequently changing the supply temperature for subsequent secondary circuits.

The specific feature of an active one-pipe system is the utilization of a secondary pump in each secondary circuit. The twin-tee component prevents hydraulic interactions with the primary circuit nor with other secondary circuits. A flow change in the primary circuit or other secondary circuit does not alter the flow in a secondary circuit at hand; thus, the flow is solely governed by the secondary pump itself. The serial connection of secondary circuits induces thermal interactions only.

When presented with the active one-pipe system for the first time, design engineers are most concerned by intuition with this primary temperature cascade and a remaining available power for the last terminal unit. It is a legitimate question, and the answer lies in proper design, system diversity, and control system used.

Heat transfer at a terminal unit is affected by its area, and the mass flow which varies the specific heat transfer rate. Both aspects can be optimally selected using a proper design tool such as $[26,37]$. The more diverse the system is, the less likely are the design loads demanded all at once; any load lower than the maximal improves the situation down the primary pipe. Finally, an advanced control system, such as the one presented in this paper, can plan energy expenditure along the chain to mitigate any individual comfort loss.

Several active one-pipe systems are in operation in the US and Canada. The Taco company has published over 30 commercial realizations altogether with drawings of the active one-pipe hydronic systems installed, see for example [21, 23].

Advantages of the active one-pipe hydronic systems are:

- The system contains likely only two pipe sizes/diameters; the primary and the secondary. I.e., sizing and material supply are simplified.

- Secondary loops are hydraulically separated from the primary loop, i.e., no hydraulic balancing procedures are necessary.

- Fewer pipes, connections, fittings, valves, heat transfer liquid and installer time/labor are required [27].

- One secondary pump type provides power control for a wide range of heat exchangers, i.e., the system is robust against design inaccuracies and troublesome component sizing.

- Active systems consume at least 50\% less pumping power [29] as there are no throttling components.
- There is no pumping energy dissipation on check valves and source supply/return piping compared to the active two-pipe system. Instead, the pump compensates only the pressure loss of the secondary circuit, i.e., a tiny pump is sufficient.

- Wet-rotor pumps are maintenance-free [22].

- Online remote diagnostics of the terminal unit is possible without the need for a flow meter [30].

- Thermal metering is also possible without a flow meter [30].

The disadvantages are:

- There is a low awareness and experience with the active one-pipe systems as wet rotor pumps made it possible only a couple of decades ago.

- Terminal units should be designed for individual temperature differences [26, 37]. Not considering the primary temperature cascade can lead to suboptimality; the terminal units can, however, be designed for a constant supply temperature [22].

- System designers might still remember the older passive one-pipe system affiliated with higher operational cost and poor comfort [28]. This experience may also consequently harm the reputation of the inherently distinct active one-pipe systems.

\section{Model}

Two components were modeled to conduct this study: a hydronic distribution system and a building envelope.

\subsection{Hydronic system model}

The active one-pipe hydronic network consists of the following components: pipe, pump, twin-tee, heat exchanger and a heat source.

Pipe imposes resistance to fluid flow proportional to a square of the fluid velocity. Pressure loss on the hydraulic resistance in a turbulent region may be approximated by

$$
\Delta p_{\text {pipe }}=K \dot{m}^{2} \text {, }
$$

where $K\left[\mathrm{~Pa} \mathrm{~h}^{2} \mathrm{~kg}^{-2}\right]$ is a hydralic resistance coefficient and $\dot{m}\left[\mathrm{~kg} \mathrm{~s}^{-1}\right]$ is the fluid mass flow.

Pumps are the centerpieces of active hydronic systems. Flow through a heat exchanger is regulated by pump speed adjustments. A second order polynomial models its pressure-flow characteristics and pump affinity laws govern the pump speed dependence

$$
\Delta p_{\text {pump }}=p_{0} s^{2}+p_{1} s \dot{m}+p_{2} \dot{m}^{2},
$$

where $p_{0}, p_{1}, p_{2}$ are pump polynomial coefficients and $s \in\langle 0,1\rangle$ is a speed ratio [43].

Twin-tee is sometimes also referred to as closely-spacedtees or a double-T. Here, two T-shaped fittings are located on the primary pipe no more than five pipe diameters apart [24]. The pressure difference between the branch pipes is in this case considered negligible

$$
\Delta p_{\text {twin-tee }}=0 \text {. }
$$

Heat exchangers or terminal units are points where the heat transported through the hydronic distribution network is emitted to a thermal zone. Dynamics of the heat exchanger is neglected in the model as its settling time is short compared to a controller sampling time/ building dynamics. Steady-state behavior is modeled by the NTU analysis [13] 


$$
\dot{Q}_{\mathrm{hx}}=\epsilon \dot{C}_{\mathrm{min}}\left(T_{\mathrm{si}}-T_{\mathrm{z}}\right) \text {, }
$$

where $\dot{Q}[\mathrm{~W}]$ is the heat flow rate, $T_{\mathrm{si}}\left[{ }^{\circ} \mathrm{C}\right]$ is the input liquid temperature (secondary circuit inlet), $T_{z}\left[{ }^{\circ} \mathrm{C}\right]$ is the input air temperature (zone temperature), $\dot{C}_{\min }\left[\mathrm{W} \mathrm{K}^{-1}\right]$ is the smaller of the capacity rates on the air and liquid side

$$
\dot{C}_{\min }=\min \left(\dot{C}_{\mathrm{w}}, \dot{C}_{\mathrm{a}}\right)
$$

where the capacity rates themselves are

$$
\begin{gathered}
\dot{C}_{\mathrm{w}}=c_{p} \dot{m}_{\mathrm{s}} \\
\dot{C}_{\mathrm{a}}=c_{V} \dot{V}_{\mathrm{a}}
\end{gathered}
$$

with $c_{\mathrm{p}}\left[\mathrm{J} \mathrm{kg}^{-1} \mathrm{~K}^{-1}\right]$ being the liquid specific heat per unit mass, $\dot{m}_{\mathrm{s}}\left[\mathrm{kg} \mathrm{s}^{-1}\right]$ liquid mass flow rate (secondary circuit flow), $c_{\mathrm{V}}$ standart air specific heat per unit volume and $\dot{V}_{\mathrm{a}}\left[\mathrm{m}^{3} \mathrm{~s}^{-1}\right]$ volumetric air flow. The effectiveness $\epsilon[-]$ is defined by a flow arrangement; a cross-flow- $\dot{C}_{\text {max }}{ }^{-}$ unmixed- $\dot{C}_{\min }$-mixed arrangement was chosen and is defined as

$$
\epsilon=1-\exp \left(C_{\mathrm{r}}^{-1}\left(1-\exp \left(-C_{\mathrm{r}} h_{\mathrm{tot}} \dot{C}_{\mathrm{min}}^{-1}\right)\right)\right.
$$

The last variable to define for the heat exchanger model is the heat exchange coefficient

$$
h_{\mathrm{tot}}=\left(h_{\mathrm{w}}^{-1}+h_{\mathrm{a}}^{-1}\right)^{-1},
$$

which is a series connection of two thermal transmittances: the liquid to body coefficient $h_{\mathrm{w}}\left[\mathrm{W} \mathrm{K}^{-1}\right]$ and the body to air coefficient $h_{\mathrm{a}}\left[\mathrm{W} \mathrm{K}^{-1}\right]$. From the work of Nusselt and others it follows, that the heat exchange coefficient on the inner surface of a pipe can be modeled as

$$
h_{\mathrm{w}}=\theta_{1}^{\mathrm{w}}\left(\dot{m}_{\mathrm{w}}\right)^{\theta_{2}^{\mathrm{w}}}
$$

where $\theta^{\mathrm{w}}$ are setup dependent parameters

The body to air heat exchange coefficient is modeled as a second order polynomial in $\dot{V}_{a}$ (air flow)

$$
h_{\mathrm{a}}=\theta_{0}^{\mathrm{a}}+\theta_{1}^{\mathrm{a}} \dot{V}_{\mathrm{a}}+\theta_{2}^{\mathrm{a}} \dot{V}_{\mathrm{a}}^{2},
$$

where $\theta^{\mathrm{a}}$ are setup dependent parameters. For a thorough explanation and a heat exchanger coefficient fitting process see [25].

Heat source considered in this paper is an ideal heat source capable of maintaining any desired supply temperature regardless of flow or return temperature variation. Its hydronic resistance is neither considered as the primary circulator is also idealized; i.e., considered to have the capability of setting the primary flow instantly to its reference value.

The heat exchanger branches in the one-pipe hydronic network are connected in series. This way, the secondary circuits are hydraulically separated, but consequently, also, the primary supply stream loses its energy further down the pipe. This relation may be expressed as mixing at the twin-tee or as a loss of secondary energy in the primary stream. The primary outlet temperature of a $z$ branch is

$$
T_{\text {po }}^{Z}=T_{\text {po }}^{z-1}-\dot{Q}_{\mathrm{hx}}^{z}\left(c_{\mathrm{p}} \dot{m}_{\mathrm{p}}\right)^{-1}, \forall z \in Z
$$

where $T_{p o}^{0}=T_{b o}\left[{ }^{\circ} \mathrm{C}\right]$ is the heat supply (boiler) outlet temperature, $z \in Z$ is a specific zone out of the set of all zones/branches $Z, z-1$ stands for a preceding branch in the direction of the primary flow $\dot{m}_{p}\left[\mathrm{~kg} \mathrm{~s}^{-1}\right]$. The primary flow is always considered greater then all secondary flows

$$
\dot{m}_{\mathrm{p}}>\dot{m}_{\mathrm{s}}^{z}, \forall z \in Z
$$

and then each secondary inlet temperature equals the primary outlet temperature of the preceding branch

$$
T_{\mathrm{si}}^{Z}=T_{\mathrm{po}}^{z-1}, \forall z \in Z .
$$

\subsection{Building model for control purposes}

A building model for control purposes used in this work adopts the widely-used RC thermal-electric analogy approach [19, 31]. Heat resistance (or similarly conductance) relates conductive heat flow to temperature gradient

$$
\dot{Q}=\Delta T / R,
$$

where $\dot{Q}[\mathrm{~W}]$ is the heat flow, $\Delta T[\mathrm{~K}]$ is a temperature difference and $R\left[\mathrm{~K} \mathrm{~W}^{-1}\right]$ is a thermal resistance. Temperature states are held by the $\mathrm{C}$ components whose changes are governed by the Fourier's law

$$
C \dot{\mathrm{T}}=\sum_{\forall n} \dot{Q}_{n},
$$

where $C\left[\mathrm{~J} \mathrm{~K}^{-1}\right]$ is a heat capacity and $T\left[{ }^{\circ} \mathrm{C}\right]$ is the temperature state.

The main envelope dynamics modeled by this approach as validated for example in $[31,32]$. The resulting dynamic model is linear and may be, after discretization, represented by the following state space model

$$
\begin{aligned}
\boldsymbol{x}_{k+1} & =\boldsymbol{A} \boldsymbol{x}_{k}+\boldsymbol{B} \boldsymbol{u}_{k}+\boldsymbol{B}_{\mathrm{d}} \boldsymbol{d}_{k} \\
\boldsymbol{y}_{k} & =\boldsymbol{C} \boldsymbol{x}_{k}
\end{aligned}
$$

where $\boldsymbol{x}$ is a state vector, $\boldsymbol{u}$ is an input vector consisting of heat exchanger heat flows $\dot{Q}_{\mathrm{hx}}^{z}, \boldsymbol{d}$ is a disturbance vector composed of solar gains $\dot{Q}_{\text {sol }}^{z}$ and an environment temperature $T_{\text {env }}$. Output vector $\boldsymbol{y}$ is a composition of zone temperatures $T_{z}^{z}$. The model discrete time steps are $t_{k}=t_{0}+k T_{\mathrm{s}}$, where $T_{\mathrm{s}}$ is the step size and $k$ is a sequence index.

Matrices $\boldsymbol{A}, \boldsymbol{B}, \boldsymbol{B}_{\mathrm{d}}, \boldsymbol{C}$ may be found by standard calibration techniques such as the prediction error method (PEM), subspace identification (4SID) etc. The model in this paper was calibrated by a distributed grey-box approach [20]. More on the topic in $[5,18,20]$.

\section{Model predictive control}

Heating control systems were traditionally on/off zone controllers switching an HVAC actuator on or off. Nowadays also proportional-integrational (PI) controllers are frequent. They control HVAC actuators in a continuous range of $0-100 \%$ to lessen wear of hardware components and possibly to raise comfort levels.

Most recently model predictive controllers (MPC) are being studied and tested. Some realizations hold their benefits for about 15 consecutive years now [8, 16, 33]. In contrast to the above approaches, MPC integrates all the available sensor, actuators as well as weather and internal gain information together into a coherent, mathematically founded optimization problem. The controller seeks the optimal actuator settings to minimize for example the energy consumption while still maintaining comfort levels or other constraints on the environment and the equipment itself.

The optimization problem in general is

$$
\begin{array}{r}
\boldsymbol{v}^{*}=\arg \min _{\boldsymbol{v}} \mathcal{J} \\
\text { s.t. } \mathcal{C},
\end{array}
$$

where $v$ are the decision variables over which the objective functional $\mathcal{J}$ is minimized subject to a constraint set $\mathcal{C}$. 


\subsection{Objective function $\mathcal{J}$}

The objective function

$$
\mathcal{J}=\sum_{k=1}^{N} \sum_{i=1}^{4} \mathcal{J}_{k}^{i}
$$

is composed of several functionals $\mathcal{J}^{i}$ shaping the optimization outcome over the future predicted behaviour on the prediction horizon $N$.

A reference funnel tracking functional is responsible for driving the model outputs to the desired reference range

$$
\mathcal{J}_{k}^{1}=\left\|\boldsymbol{y}_{k}-\boldsymbol{s}_{k}^{\mathrm{r}}\right\|_{\boldsymbol{Q}_{1}}^{2},
$$

where $\|\boldsymbol{a}\|_{\boldsymbol{Q}}^{2} \stackrel{\text { def }}{=} \boldsymbol{a}^{\mathbf{T}} \boldsymbol{Q} \boldsymbol{a}$ represents a second vector norm weighted over a matrix $\mathbf{Q}$ and $\boldsymbol{s}_{\mathbf{r}}$ is a reference slack vector defined later. An input effort (power) is minimized by the functional

$$
\mathcal{J}_{k}^{2}=\left\|\boldsymbol{u}_{k}\right\|_{Q_{2}}^{2}
$$

and smooth operation is attained by penalizing an input change by

$$
\mathcal{J}_{k}^{3}=\left\|\boldsymbol{u}_{k-1}-\boldsymbol{u}_{k}\right\|_{Q_{3}}^{2}
$$

The primary flow is minimized by

$$
\mathcal{J}_{k}^{4}=\left\|\dot{m}_{\mathrm{p}, k}\right\|_{Q_{4}}^{2}
$$

\subsection{Constraints $\mathcal{C}$}

The objective function is used to shape the optimization outcome. The constraint set encodes the knowledge of system behavior and allows to put bounds on optimization variables. The constraint set is composed of a multitude of constraints

$$
\mathcal{C}=\bigcup_{\forall i, k} \mathcal{C}_{k}^{i}
$$

The first is an equality constraint establishing the model dynamics (14-15)

$$
\mathcal{C}_{k}^{1}: \boldsymbol{x}_{k+1}-\boldsymbol{A} \boldsymbol{x}_{k}-\boldsymbol{B} \boldsymbol{u}_{k}-\boldsymbol{B}_{\mathrm{d}} \boldsymbol{d}_{k}=\mathbf{0} .
$$

Reference slack variable vector is constrained to a reference trajectory vector range

$$
\mathcal{C}_{k}^{2}: \underline{\boldsymbol{r}}_{k}<\boldsymbol{s}_{k}^{\mathrm{r}}<\overline{\boldsymbol{r}}_{k}
$$

where the underbar and overbar accents stand for lowerand upper-funnel limits, respectively.

The next constraints encode the one-pipe hydronic network relations into the optimization. The equation (4) with all its related equations (5-11) combined with (14) relates the heat transfer capabilities to the zone temperature and secondary mass flow

$$
\mathcal{C}_{k}^{3}: \dot{Q}_{\mathrm{hx}}^{z}-\epsilon \dot{C}_{\min }\left(T_{\mathrm{po}}^{z-1}-T_{\mathrm{z}}^{z}\right)=0, \forall z \in Z,
$$

where $\dot{Q}_{\mathrm{hx}}^{z}$ is a $z^{\text {th }}$ element of the input vector $\boldsymbol{u}$.

Branch to branch coupling, manifested by decaying primary flow energy, is captured by (12)

$$
\mathcal{C}_{k}^{4}: T_{\text {po }}^{z}-T_{\text {po }}^{z-1}+\dot{Q}_{\mathrm{hx}}^{z}\left(c_{\mathrm{p}} \dot{m}_{\mathrm{p}}\right)^{-1}=0, \forall z \in Z .
$$

For $\mathcal{C}^{4}$ to hold, we must also constraint the primary flow to exceed secondary flows (13), that are also supposed to be greater than zero

$$
\mathcal{C}_{k}^{5}: 0<\dot{m}_{\mathrm{s}}^{z}<\dot{m}_{\mathrm{p}}, \forall z \in Z .
$$

Note that regardless not stated explicitly, the time instance of all variables in the constraints $\mathcal{C}^{3}, \mathcal{C}^{4}, \mathcal{C}^{5}$ is ' $t_{k}$ '. Also, note that usual box constraints are also part of $\mathcal{C}$.

\subsection{Implementation}

The control mechanism of the MPC is to find the optimal solution $\boldsymbol{v}^{*}$ to the problem (17) and to apply the first optimal input to the system; then after one sampling period, measure system outputs, optionally estimate the current system state, and calculate optimal solution again. The problem is non-linear due to nonlinear functional constraints and the discontinuity (5) involved.

The problem was implemented by the multiple shooting method [40], where the state at each sampling time is included as a decision variable. This approach generally improves convergence but also increases the NLP size considerably. The optimization variable vector is therefore composed of primary and secondary flows, states and the reference slack variables

$$
\boldsymbol{v}=\bigcup_{k=1}^{N}\left\{\dot{m}_{\mathrm{p}, k}, \dot{\boldsymbol{m}}_{\mathrm{s}, k}, \boldsymbol{x}_{k}, \boldsymbol{s}_{k}^{\mathrm{r}}\right\}
$$

where $\dot{\boldsymbol{m}}_{\mathrm{s}, k}=\bigcup_{z \in Z} \dot{m}_{\mathrm{s}}^{z}(k)$ is a vector of all secondary flows at time $k$.

The implementation was first carried out in the YALMIP framework [39] using the Gurobi solver [38]. This approach involving numerical gradients, however, provided insufficient results in terms of accuracy and time demand. A second implementation using algorithmic differentiation from the CasADi framework [4] in combination with the IPOPT solver [42], on the other hand, yielded a consistent, precise and prompt solution. Further information in [41].

\section{Simulation}

The proposed control approach will be validated on a real building simulation scenario. The building of choice is the Fenix Trading office center (Fig. 2) located in Jesenik, the Czech Republic. It is an NZEB building with hybrid PV panels and yearly energy consumption of $27 \mathrm{kWh}$ [34]. UCEEB [36] was active in energy system design and energy performance monitoring and analysis [34]. An EnergyPlus simulation model of the building (developed by M. Urban, UCEEB) that was used for energy predictions in [34] is without qualitative modifications also utilized in this study. The MPC control is realized on a second floor (four thermal zones), see Fig. 3. The rest of the building is kept at a constant temperature range 20$25^{\circ} \mathrm{C}$ by local PI controllers.

The heating appliances used in the building are electrical heaters. Their power is for our purposes set to the power obtained from the one-pipe hydronic heating network developed open source design tool [37] published in a complementary paper [26].

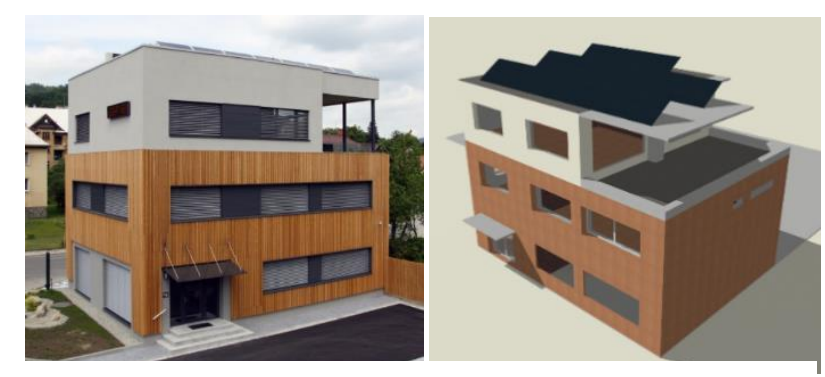

Fig. 2. Fenix building. Credits :Fenixgroup, Miroslav Urban 


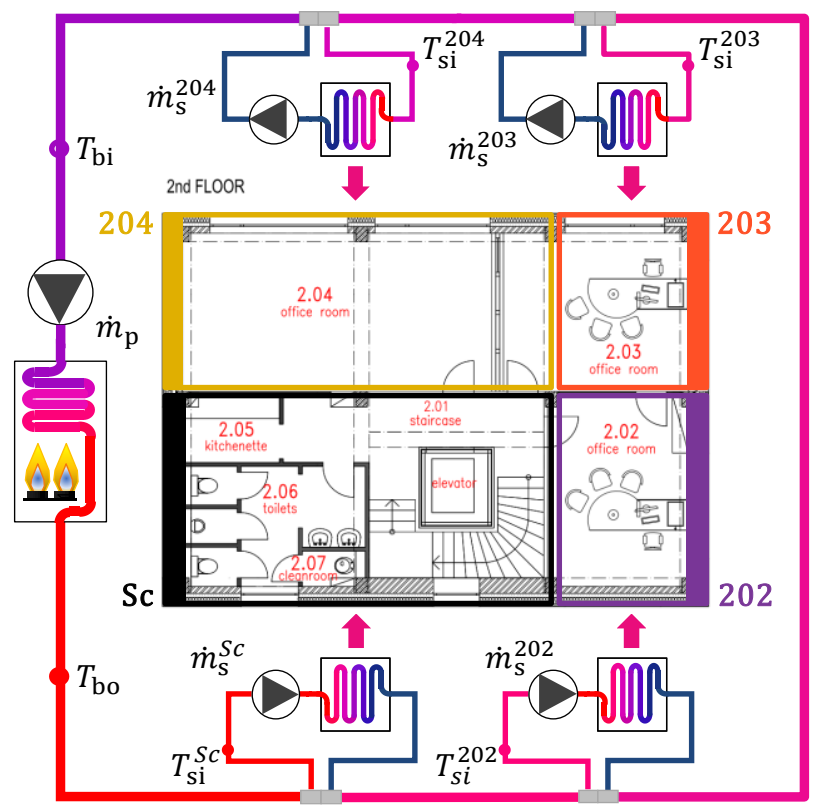

Fig. 3. Onepipe hydronic heating installation for the $2^{\text {nd }}$ floor. Note the zone color frames match the line colors in the simulation results presented further.

The design loads, for conditions $T_{\text {env }}=-12{ }^{\circ} \mathrm{C}, T_{\mathrm{z}}=$ $22^{\circ} \mathrm{C}, T_{\mathrm{bo}}=60{ }^{\circ} \mathrm{C}, \mathrm{T}_{\mathrm{bi}}=40^{\circ} \mathrm{C}$, were $\dot{Q}_{\mathrm{z}}^{\text {design }}=(1450$, $650,800,1350)[\mathrm{W}]$ for the staircase (Sc), office director room (202), office assistant room (203) and the office room (204), respectively. The design sizes for catalogue values $90 / 70 / 20^{\circ} \mathrm{C}$ are $(2800,1550,2150,4750)[\mathrm{W}]$. The heat exchangers are modelled by 20 -state plug-flow finite element models. The flow through the secondary circuits is enforced to equal the flow reference $\dot{m}_{s}^{z}$. Note that the mass flow may be inferred from pump measurements [30] and as such may be, by varying pump speed controlled, to the reference level. Boiler supply temperature is $60^{\circ} \mathrm{C}$.

Matlab/Simulink was used to perform the simulation; the simulation model is depicted in Fig. 5. Real-time cosimulation of the EnergyPlus model was executed by a developed open source EnergyPlus Co-simulation Toolbox [35]. The model timestep is $300 \mathrm{~s}$.

\subsection{Baseline control}

The baseline control is performed by PI controllers; one for primary flow and four for each secondary flow (Fig. 5). The primary flow is controlled such that the boiler return temperature $T_{b i}$ is always at least $40^{\circ} \mathrm{C}$. This forces a sufficient temperature potential for the last terminal unit to operate correctly. Primary flow is also overridden by the maximal secondary flow to prevent backflow at the secondary circuit. Integrator state is tracking the output to ensure bumpless control.

Secondary PI controllers steer the temperature to the lower limit of the reference funnel (for comparison with the MPC). The flow-to-power characteristic of a heat exchanger is nonlinear with a steep rise at the low flow. Equal-percentage transformation curve known from hydronic control valves has been added to linearize the characteristics and improve control performance.
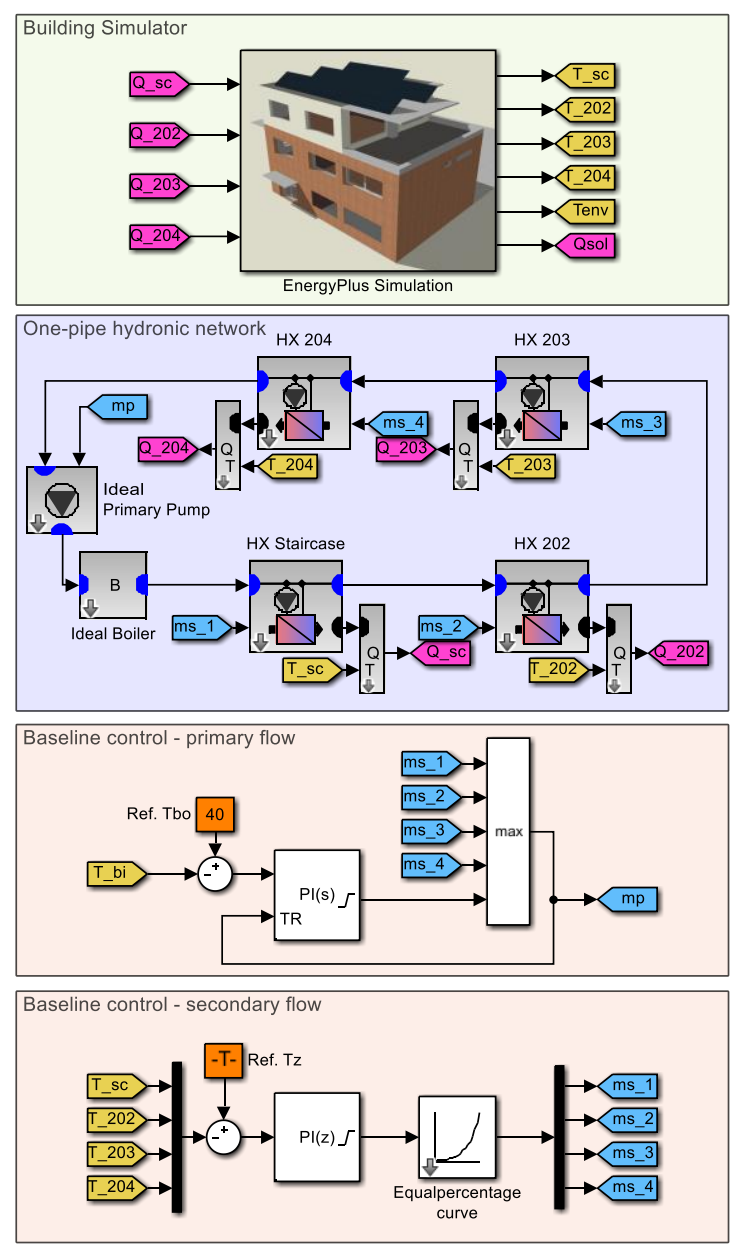

Fig. 5. Software realization of the proposed baseline control scheme. Building is simulated by EnergyPlus, one-pipe hydronic network and controller by Matlab/Simulink.

\subsection{MPC}

A predictive controller uses a mathematical model to predict system behavior and optimize control actions. The building model for control purposes here uses a CRC bridge structure for zone models and the simplest oneresistance R1C0 structure for wall models [20]. The model was calibrated on a 10-day interval and validated on a different 2-day interval; mean identification fit $86.6 \%$ (NRMSE), mean validation fit for 6-hour predictions $82.9 \%$ (NRMSE).

MPC also requires an initial state at each step. A Kalman filter with an unknown input observer extension estimates the state. The control scheme is depicted in Fig. 4. MPC sampling is $600 \mathrm{~s}$, prediction horizon $N=30$ ( 5 hours).

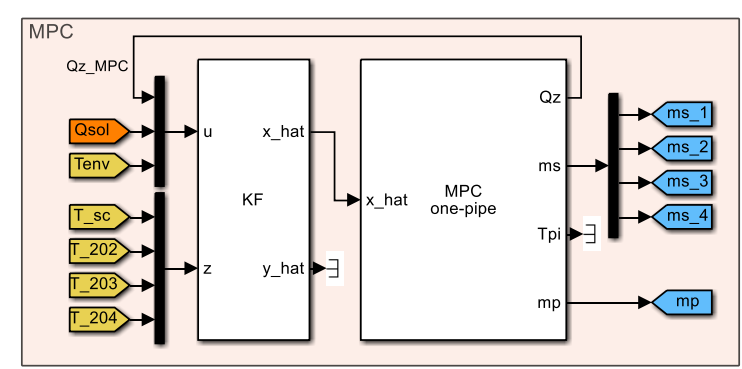

Fig. 4. Software realization of the proposed MPC control scheme. 

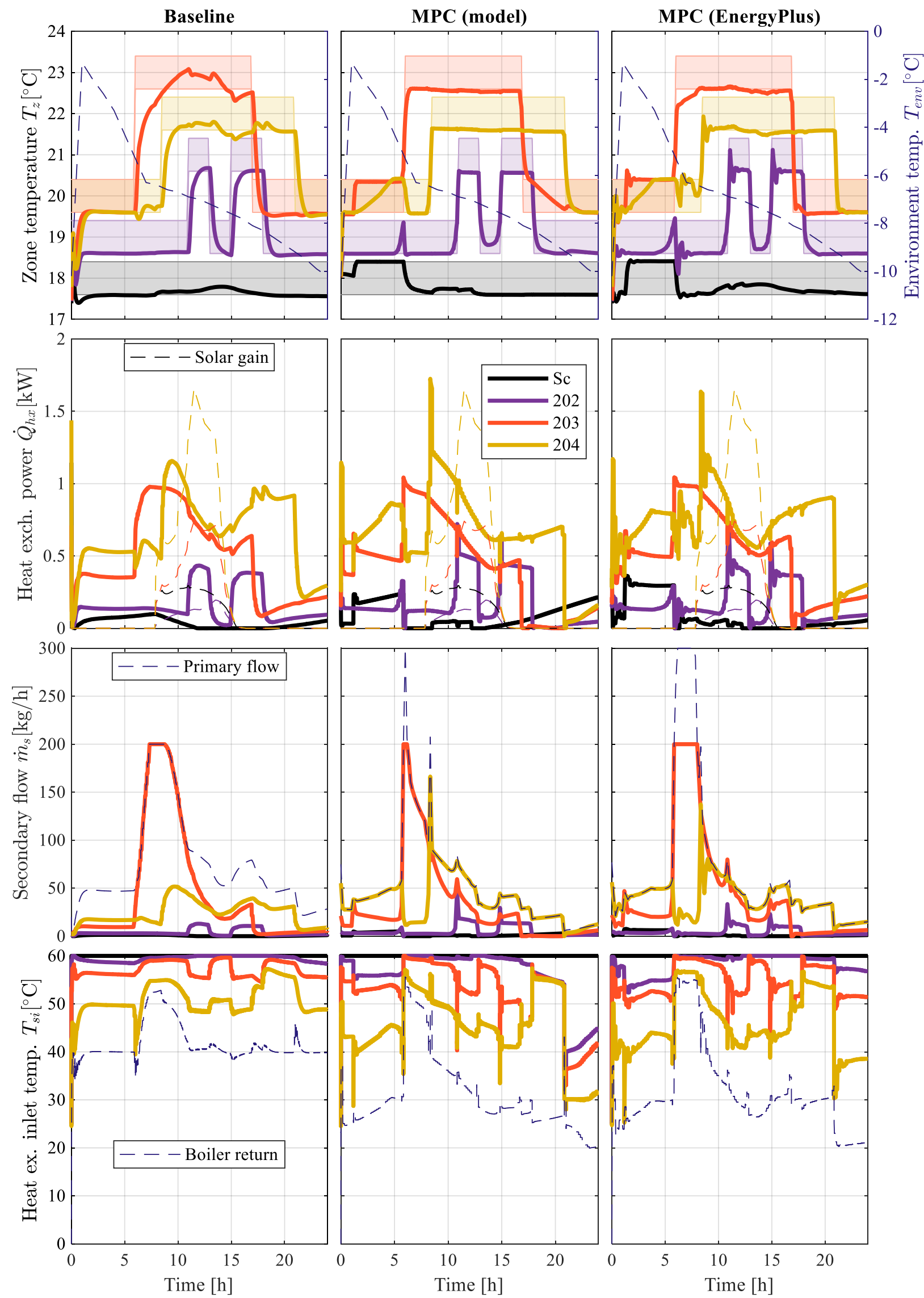

Fig. 6. Comparison of three control results: the baseline control by PI controllers (left), MPC controlling the identified state space model through the onepipe network model (middle) and MPC controlling the EnergyPlus model acompanied by the Kalman state estimator (right). Note the $y$-axis for the environment temperature (dashed) positioned on the right of the first row. Solid lines represent the four zones : Staircase (Sc), room 202 (202), room 203 (203) and room 204 (204). 


\subsection{Results}

Figure 6 shows results for three simulation settings; the first column pertains to the baseline control, the second column to a setting, where the building is simulated by the building control model itself; the heat flows are however still generated by the one-pipe network model. The third column pertains to the MPC control of the one-pipe network and the actual EnergyPlus model. The building was warmed up (10-day warming period).

The baseline primary controller is tracking the return temperature reference; it is overridden by the heat up of the room 203 at time $6 \mathrm{~h}$. Such override, however, is not very realistic in real field conditions; this override increases the performance of the baseline control to a comparable level. All the room temperature references are eventually reached, but as there is no planning, the heat up time can't be decreased without increasing the return temperature reference and thus sacrificing heat source efficiency (lower return temperature $\rightarrow$ better).

The planning capabilities of MPC are demonstrated on the interval 1-6 $\mathrm{h}$ of the MPC on the model scenario. At time $1 \mathrm{~h}$ the reference change of room 203 appears at the end of the prediction horizon. The decision is to accumulate heat in all the zones so that when the reference change happens, all the preceding zones (Staircase \& 202) can be shut off. Then the room 203 has the highest inlet temperature and is able to raise its temperature as fast as possible. Note that the reference funnel tracking weight was put high to exaggerate this effect.

As the building control model is not precise in prediction, we can see at time 6-8 h, that the MPC on EnergyPlus is struggling to raise the room 203 temperature. The primary and secondary flows are at their bounds (300 and 200 $\mathrm{kg} / \mathrm{h}$, respectively). This also demonstrates the feedback control capabilities of the MPC.

Table 1. presents cumulative energy consumption for the three scenarios as well as an average out-of-funnel root mean square tracking error (RMSE) across the four zones and an average boiler return temperature.

Table 1. Cumulative/mean results

\begin{tabular}{|c|c|c|c|}
\hline & Baseline & $\begin{array}{c}\text { MPC } \\
\text { (model) }\end{array}$ & $\begin{array}{c}\text { MPC } \\
\text { (EnergyPlus) }\end{array}$ \\
\hline Energy $[\mathrm{kWh}]$ & 32.18 & 32.39 & 35.07 \\
\hline RMSE $\left[{ }^{\circ} \mathrm{C}\right]$ & 0.29 & 0.16 & 0.12 \\
\hline Boiler return $\left[{ }^{\circ} \mathrm{C}\right]$ & 42.4 & 31.4 & 32.09 \\
\hline
\end{tabular}

Tracking precision of the baseline control is inferior, but consequently, the energy consumption is also lower due to generally lower tracked temperatures. Despite having the MPC aggressively tracking the reference, the cumulated energy consumption is comparable to the baseline in prediction (model). When applied to the EnergyPlus model, the MPC consumption is $9 \%$ higher, but as mentioned, the energy consumption comparison is not entirely fair.

The temperature at boiler inlet ranks about $10{ }^{\circ} \mathrm{C}$ lower, which would significantly improve heat source efficiency.

\section{Conclusion}

The active (pump-driven) hydronic heating system is an emerging technology. Wet-rotor pumps are maturing, and with it this unorthodox heat distribution method becomes possible. The two-pipe as well as the one-pipe approaches each presents a novel set of challenges and benefits. To harness the most from hydronic systems, the traditional paradigm of throttling valves must be set loose.

This paper presents a predictive controller altogether with design, modeling and simulation tools applied on a small office case study. Part of the toolset is already available as an open source software.

MPC is definitely a viable option for optimal control of buildings with one-pipe hydronic systems. Further thought should, however, be also given to a robust decentralized local feedback control system provided as the default means of control.

This work has been supported by the Technology Agency of the CR, project No. TK01020024 - Hydronics 4.0 and the Ministry of Education, Youth and Sports within National Sustainability Programme I (NPU I), project No. LO1605. We would like to also express our gratitude to Miroslav Urban for providing us with the EnergyPlus simulation model and support. Further appreciations go to Jan Předota for his effort on the thesis [41] that this paper extends.

\section{References}

[1] Clean Energy for All Europeans (European Commission, 2016)

[2] Annual Energy Outlook (2017) with projection to 2050 (U.S. Energy Information Administration, 2017)

[3] Directive (EU) 2018/844 of the European Parliament and of the Council of 30 May 2018 (Official Journal of the European Union, 2018)

[4] Joel A. E. Andersson, Joris Gillis et al., CasADi -- A software framework for nonlinear optimization and optimal control, Mathematical Programming Computation (In Press, 2018)

[5] Tomáš Bäumelt, Distributed building identification (Czech Technical University in Prague, 2016)

[6] Venkatesh Chinde, Modeling and control of complex building energy systems (Iowa State University, 2018)

[7] Jiří Cígler, Model predictive control for buildings (Czech Technical University in Prague, 2013)

[8] Jiří Cígler, Dimitrios Gyalistras et al., Beyond theory: the challenge of implementing model predictive control in buildings, in: Proceedings of 11th Rehva world congress, Clima, (2013)

[9] Jiří Dostál, Lukáš Ferkl, Model predictive control of climatic chamber with on-off actuators, in: IFAC Proceedings Volumes (IFAC-PapersOnline), 44234428 (2014) 10.3182/20140824-6-ZA-1003.01571

[10] Jiří Dostál, Vladimír Havlena, Modeling, optimization and analysis of hydronic networks with decentralized pumping, in: CACS 2014 - 2014 International Automatic Control Conference, 
Conference Digest, 269-274

(2014)

10.1109/CACS.2014.7097200

[11]L. Grüne, J. Pannek, Nonlinear Model Predictive Control: Theory and Algorithms (Springer London, 2011)

[12] Ivo Herman, Štefan Knotek et al., Stability of hydronic networks with independent zone controllers, IEEE Trans. Control Syst. Technol. (2017) 10.1109/TCST.2017.2753179

[13] G. Nellis, S. Klein, Heat Transfer (Cambridge University Press, 2009)

[14]L. Perez-Lombard, J. Ortiz et al., A review on buildings energy consumption information, Energy Build. 40, (2008)

[15] Samuel Prívara, Jiří Cígler et al., Building modeling as a crucial part for building predictive control, Energy Build. 56, 8-22, (2013) 10.1016/j.enbuild.2012.10.024

[16] Samuel Prívara, Jan Široký et al., Model predictive control of a building heating system: The first experience, Energy Build. 43, 564-572, (2011) 10.1016/j.enbuild.2010.10.022

[17] Gianluca Serale, Massimo Fiorentini et al., Model predictive control (MPC) for enhancing building and HVAC system energy efficiency: problem formulation, applications and opportunities, Energies 11, 631, (2018) 10.3390/en11030631

[18]David Sturzenegger, Model predictive building climate control: Steps towards practice (ETH Zurich, 2014)

[19] Frank P. Incropera, David P. DeWitt et al., Principles of Heat and Mass Transfer (John Wiley \& Sons, 2012)

[20]Tomáš Bäumelt, Jiř́ Dostál, Distributed agent-based building model calibration, to be published in Energy \& Buildings (2019)

[21] Taco, Inc., Green municipal building uses single pipe hydronic system, PM Enginner Feb., 54, (2005)

[22] Greg Cunniff, Brett Zebra, Single-pipe systems for commercial applications, HPAC Engineering Oct., 42-46, (2006)

[23] Taco, Inc., Taco employs the latest technologies for LEED certification of its building addition, ASHRAE Journal (2009)

[24] John Siegenthaler, Modern Hydronic Heating, 3rd Edition (Cengage Learning, Inc., 2011)

[25] Jiř́i Dostál, Václav Prajzner et al., Convection Oriented Heat Exchanger Model - Identification, in: Proceedings of the 12th REHVA World Congress: volume 9, (2016)

[26] Ondřej Zlevor, Jiř́ Dostál et al., Demand-oriented hydronic heating system and an active one-pipe system design tool, in: Proceedings of the 13th REHVA HVAC World Congress, (to be published, 2019)
[27] Kirk Mescher, One-pipe geothermal design: Simplified GCHP system, ASHRAE Journal Oct., 24-40, (2009)

[28], Einrohrheizungen: Neues System für die Sanierung, HeizungsJournal 11, (2016)

[29]Zertifikat: Energieeinsparung durch dezentrales Pumpensystem Geniax (TÜV Rheinland, 2010)

[30] Heat exchanger control and diagnostic apparatus (WO2016202316 (A1), 2016)

[31]B. Lehmann, D. Gyalistras et al., Intermediate complexity model for Model Predictive Control of Integrated Room Automation, Energy Build. 58, 250 262, (2013) 10.1016/j.enbuild.2012.12.007

[32] David Sturzenegger, Dimitrios Gyalistras et al., Semi-automated modular modeling of buildings for model predictive control, in: Proceedings of the Fourth ACM Workshop on Embedded Sensing Systems for Energy-Efficiency in Buildings BuildSys '12, (2012) 10.1145/2422531.2422550

[33] Jan Široký, Frauke Oldewurtel et al., Experimental analysis of model predictive control for an energy efficient building heating system, Appl. Energy 88, 3079-3087, (2011) 10.1016/j.apenergy.2011.03.009

[34] M. Urban, M. Bejček, P. Wolf, A. Vodička, Koncept administrativní budovy jako budovy s téměř nulovou spotřebou energie, Vytápění, větrání, instalace, 26(1), 30-36, (2017) ISSN 1210-1389

[35] EnergyPlus Co-simulation Toolbox (github.com/UCEEB/EnergyPlus-co-simulationtoolbox, 2018)

[36] University Centre For Energy Efficient Buildings, CTU in Prague (uceeb.cz, 2018)

[37] Onepipe Hydronic Design Tool (github.com/UCEEB/Onepipe-Hydronic-DesignTool, 2018)

[38] Gurobi optimizer (Gurobi Optimization, LLC., 2018)

[39] J. Löfberg, YALMIP : A Toolbox for Modeling and Optimization in MATLAB, in: In Proceedings of the CACSD Conference, (2004)

[40] L. T. Biegler, Nonlinear programming: Concepts, algorithms, and applications to chemical processes (Society for Industrial and Applied Mathematics (SIAM, 3600 Market Street, Floor 6, Philadelphia, PA 19104), 2010)

[41] Jan Předota, Model predictive control for buildings with one-pipe hydronic heating (Czech Technical University in Prague, 2018)

[42] Andreas Wächter, Lorenz T. Biegler, On the implementation of an interior-point filter line-search algorithm for large-scale nonlinear programming, Math. Program. 106, 25-57, (2006) 10.1007/s10107004-0559-y

[43] Jiří Dostál, Decentralized control of hydronic building systems (thesis study) (Czech Technical University in Prague, 2015) 